\title{
Variation of facial heights among the Class I, II and III dentoskeletal relationships (Cepha- lometric study)
}

Hussain A Obaidi BDS, MD (Assist Prof)

\author{
Dept of Pedod, Orthod and Prev Dent
}

College of Dentistry, University of Mosul

\begin{abstract}
Aims: To compare the anterior and posterior facial heights among the sexes and total sample. Mean while; to find the facial height variations among the Class I, II and III dentoskeletal groups. Materials and Methods: The sample comprised of 32 lateral cephalometric radiographs ( 16 for each sex) for each of the Class I, II and III dentoskeletal relationships. The age of the sample subjects was 15-20 years. The lateral cephalometric radiographs were traced. The total, upper and lower anterior facial heights and the total, upper and lower posterior facial heights were measured. Results: No significant differences among the both sexes and total sample for the dentoskeletal groups were demonstrated. All the facial heights appeared significantly greater in Class II group than Class I group except upper anterior, upper posterior and lower posterior facial heights and was significantly higher than Class III group in upper anterior, lower anterior and upper posterior facial height. Class III group displayed significantly lower value in total facial height than Class I group and significantly larger value in lower posterior facial height than of Class I group and Class II group. Conclusion: The facial heights are not affected by the sex variation, but there are certain variations in facial heights among the dentoskeletal groups.

Key Words: Facial height, dentoskeletal relationships, sexes variation.
\end{abstract}

Obaidi HA. Variation of facial heights among the Class I, II and III dentoskeletal relationships (Cephalometric study). Al-Rafidain Dent J. 2006; 6(2): 98-105.

Received: 20/6/2005 Sent to Referees: 21/6/2005

Accepted for Publication: 1/12/2005

\section{INTRODUCTION}

The facial heights of young adult subject are regarded a potential determinant in developing the facial harmony and the esthetic. Moreover, they are essential factors in designing the facial type.

The facial heights are affected by the growth of the cranial base. The upper face is under the influence of the cranial base inclination. It moves upward and downwa$\mathrm{rd}$, the lower face moves downward and forward, the divergent growth pattern permits vertical growth of the dentoalveolar component. $^{(1)}$

At birth the height of the cranium and the width of the face are closest to the adu1t size. ${ }^{(2)}$ The endochondral growth of the cranial base and the growth of the sutures and the nasal septum of the upper face stimulate the downward and forward growth of the maxillary complex, growth at the condyle together with significant alveolar growth contribute to the height of the mandible. $^{(3)}$
Mandibular growth in width, which is accomplished relatively early in the child shows less change than the vertical and sagittal dimensions in which change is significant. ${ }^{(4)}$ This is favored for the orthodontist who is planning to change the facial height and the sagittal dimension of the face.

Woodside $^{(5)}$ reported that the mandible showed significant growth spurts in the prepubertal and pubertal periods. In his study, he pointed out that the good growth spurts seem to be sex-linked. The greatest increments of growth are actual at 3 years age level, the second peak is formed at 6-7 years in girls and 7-9 years in boys, the third peak is at 11-12 years in girls and 1415 years in boys.

Ibrahim et al. ${ }^{(6)}$ found that the total increase of the vertical facial measurements in the 10-12 years age period were greater than in the 12-14 years age period for female subjects, whereas the total increase in the 12-14 years age period were greater than in the $10-12$ years age period for 
male subjects.

It is eared that one must take into consideration the fourth dimension (time). This is of vital importance to the orthodontist, who must schedule his treatment planning so that it coincides with the most favorable growth period.

The aim of this study was to assess the value of the variation of the facial heights among the dentoskeletal of Classes I, II and III for Iraqi young adults live in Mosul City.

\section{MATERIALS AND METHODS}

The sample consisted of 96 lateral cephalometric radiographs for the patients of Classes I, II and III dentoskeletal relationship, of age 15-20 years, for Iraqi subjects live in Mosul City, who were attending the Pedodontics, Orthodontics and Preventive Dentistry Department, Dentistry College, Mosul University.

The sample subjects were grouped into the Classes I, II and III dentoskeletal relationships (the Classes I, II and III were associated with ANB angle zero-2 degrees, more than 2 degrees and less than zero degrees respectively). Each of these groups was divided into males and females (16 subjects for each sex).

The lateral cephalometric radiographs were traced and marked the angles (SNA, $\mathrm{SNB}, \mathrm{ANB})$ as defined by the authors, ${ }^{(7,8)}$ total anterior facial height (TAFH; N-Me) as indicated by the researchers, ${ }^{(9,10)}$ upper anterior facial height (UAFH; N-ANS) as depended in the studies, ${ }^{(10,11)}$ lower anterior facial (LAFH; ANS-Me) and total posterior facial height (TPFH; S-Go) as utilized in the researches, ${ }^{(10,12)}$ upper posterior facial height (UPFH; the vertical distance from PNS to SN line) as used by the authors, ${ }^{(10,13)}$ and the lower posterior facial height (LPFH; Ar-Go) and called rumas height as defined by the researchers ${ }^{(11,14)}$ (Figure 1).

The facial heights of the all sample subjects were measured and recorded. The data were analyzed by using the descriptive analysis including the mean, standard deviation, minimum and maximum values and the analysis of variance (ANOVA) and Duncan's Multiple Range Test analyses were applied to detect the variances of these parameters among male, female and total sample in addition to find the variances among the Classes I, II and III groups.

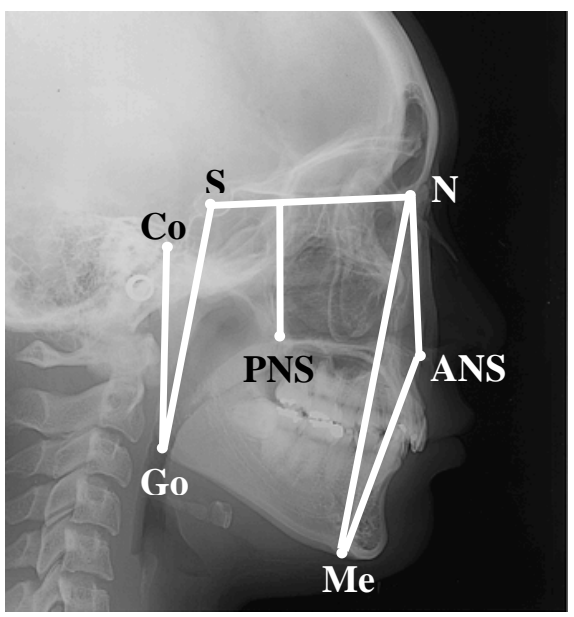

Figure (1): The facial heights

$\mathrm{N}-\mathrm{Me}$ : Total anterior facial height. N-ANS: Upper anterior facial height. ANS-Me: Lower anterior facial height. S-Go: Total posterior facial height. PNS $\perp$ SN: Upper posterior facial height. Co-Go: Lower posterior facial height.

\section{RESULTS}

The descriptive analysis (mean value, standard deviation, minimum and maximum values) of the facial heights of the Class I, II and III dentoskeletal relationships for male and female and total sample subjects were expressed in Tables (1), (2) and (3).

In Class I, II and III groups, all facial height parameters appeared greater mean value in male than female and total sample. Meanwhile, Class II group showed higher mean value than the Class I and III groups, except UPFH and LPFH for both sexes and total sample. Class I group displayed larger mean value in UPFH than in Class III group for both sexes and total sample. While Class III group disclosed more mean value in LPFH than in Class I group for both sexes and total sample.

The ANOVA and Duncan's analyses of facial height among both sexes and total sample showed that the mean values of the facial height were not significant $(p>$ 0.05 ). The ANOVA analysis of the facial heights among the dentoskeletal groups appeared significant difference $(p \leq 0.05)$ and Duncan's analysis (Table 4 and Figure 2) revealed that the Class I group was sig- 
Table (1): Descriptive analysis and sex variation of analysis of facial heights in Class I group

\begin{tabular}{cccccccc}
\hline $\begin{array}{c}\text { Facial Height } \\
\text { Parameters }\end{array}$ & Sex & $\begin{array}{c}\text { Sample } \\
\text { No. }\end{array}$ & $\begin{array}{c}\text { Mean } \\
\text { Value }\end{array}$ & \pm SD & Significance & $\begin{array}{c}\text { Minimum } \\
\text { Value }\end{array}$ & $\begin{array}{c}\text { Maximum } \\
\text { Value }\end{array}$ \\
\hline \multirow{2}{*}{ Total Anterior } & Male & 16 & 128.6 & 2.6 & $\mathrm{~A}$ & 118.5 & 136.5 \\
Facial Height & Female & 16 & 126.2 & 2.1 & $\mathrm{~A}$ & 115.5 & 134.5 \\
& Total & 32 & 127.4 & 2.4 & $\mathrm{~A}$ & 115.5 & 136.5 \\
\hline \multirow{2}{*}{ Upper Anterior } & Male & 16 & 54.2 & 3.1 & $\mathrm{~A}$ & 48.5 & 59.5 \\
Facial Height & Female & 16 & 53.4 & 2.8 & $\mathrm{~A}$ & 45.5 & 57.5 \\
& Total & 32 & 53.8 & 2.9 & $\mathrm{~A}$ & 45.5 & 59.5 \\
\hline \multirow{2}{*}{ Lower Anterior } & Male & 16 & 71.2 & 3.2 & $\mathrm{~A}$ & 68.5 & 81.0 \\
Facial Height & Female & 16 & 69.3 & 3.1 & $\mathrm{~A}$ & 66.5 & 80.5 \\
& Total & 32 & 70.3 & 3.1 & $\mathrm{~A}$ & 66.5 & 81.0 \\
\multirow{2}{*}{ Total Posterior } & Male & 16 & 90.3 & 2.8 & $\mathrm{~A}$ & 82.5 & 97.5 \\
Facial Height & Female & 16 & 87.5 & 1.9 & $\mathrm{~A}$ & 81.5 & 95.0 \\
& Total & 32 & 88.9 & 2.3 & $\mathrm{~A}$ & 81.5 & 97.5 \\
\hline \multirow{2}{*}{ Upper Posterior } & Male & 16 & 48.4 & 3.4 & $\mathrm{~A}$ & 42.5 & 56.5 \\
Facial Height & Female & 16 & 44.8 & 2.9 & $\mathrm{~A}$ & 35.5 & 56.0 \\
& Total & 32 & 46.6 & 3.2 & $\mathrm{~A}$ & 35.5 & 56.5 \\
\hline \multirow{2}{*}{ Lower Posterior } & Male & 16 & 58.3 & 2.4 & $\mathrm{~A}$ & 50.5 & 66.5 \\
Facial Height & Female & 16 & 55.2 & 2.6 & $\mathrm{~A}$ & 44.0 & 63.5 \\
& Total & 32 & 56.8 & 2.5 & $\mathrm{~A}$ & 44.0 & 66.5 \\
\hline Anysis of
\end{tabular}

Analysis of variance of the facial height among the male, female and total sample was not significant $(p>0.05)$. Duncan's analysis of the facial height among the male, female and total sample was not significant $(p>0.05)$. All measurements were in millimeters.

SD: Standard deviation.

Different letters vertically mean significant difference $(p \leq 0.05)$.

Same letters vertically mean no significant difference $(p>0.05)$.

Table (2): Descriptive analysis and sex variation of analysis of facial heights in Class II group

\begin{tabular}{cccccccc}
\hline $\begin{array}{c}\text { Facial Height } \\
\text { Parameters }\end{array}$ & Sex & $\begin{array}{c}\text { Sample } \\
\text { No. }\end{array}$ & $\begin{array}{c}\text { Mean } \\
\text { Value }\end{array}$ & \pm SD & Significance & $\begin{array}{c}\text { Minimum } \\
\text { Value }\end{array}$ & $\begin{array}{c}\text { Maximum } \\
\text { Value }\end{array}$ \\
\hline \multirow{2}{*}{ Total Anterior } & Male & 16 & 136.4 & 1.6 & $\mathrm{~A}$ & 124.5 & 139.0 \\
Facial Height & Female & 16 & 134.2 & 1.4 & $\mathrm{~A}$ & 122.5 & 138.5 \\
& Total & 32 & 135.3 & 1.5 & $\mathrm{~A}$ & 122.5 & 139.0 \\
\hline \multirow{2}{*}{ Upper Anterior } & Male & 16 & 57.1 & 1.8 & $\mathrm{~A}$ & 51.5 & 63.5 \\
Facial Height & Female & 16 & 55.8 & 1.6 & $\mathrm{~A}$ & 48.5 & 62.0 \\
& Total & 32 & 56.5 & 1.7 & $\mathrm{~A}$ & 48.5 & 63.5 \\
\hline \multirow{2}{*}{ Lower Anterior } & Male & 16 & 78.3 & 2.2 & $\mathrm{~A}$ & 71.5 & 85.5 \\
Facial Height & Female & 16 & 76.9 & 2.4 & $\mathrm{~A}$ & 70.0 & 83.0 \\
& Total & 32 & 77.6 & 2.3 & $\mathrm{~A}$ & 70.0 & 85.5 \\
\multirow{2}{*}{ Total Posterior } & Male & 16 & 96.6 & 1.8 & $\mathrm{~A}$ & 88.5 & 99.5 \\
Facial Height & Female & 16 & 94.8 & 2.4 & $\mathrm{~A}$ & 76.5 & 97.5 \\
& Total & 32 & 95.7 & 2.1 & $\mathrm{~A}$ & 76.5 & 99.5 \\
\hline \multirow{2}{*}{ Upper Posterior } & Male & 16 & 46.6 & 2.3 & $\mathrm{~A}$ & 36.5 & 51.5 \\
Facial Height & Female & 16 & 42.9 & 1.9 & $\mathrm{~A}$ & 34.5 & 48.5 \\
& Total & 32 & 44.8 & 2.1 & $\mathrm{~A}$ & 34.5 & 51.5 \\
\hline \multirow{2}{*}{ Lower Posterior } & Male & 16 & 51.2 & 1.9 & $\mathrm{~A}$ & 44.5 & 58.0 \\
Facial Height & Female & 16 & 49.8 & 2.2 & $\mathrm{~A}$ & 43.0 & 56.0 \\
& Total & 32 & 50.5 & 2.1 & $\mathrm{~A}$ & 43.0 & 58.0 \\
\hline Anlysis
\end{tabular}

Analysis of variance of the facial height among the male, female and total sample was not significant $(p>0.05)$. Duncan's analysis of the facial height among the male, female and total sample was not significant $(p>0.05)$.

All measurements were in millimeters.

SD: Standard deviation.

Different letters vertically mean significant difference $(p \leq 0.05)$.

Same letters vertically mean no significant difference $(p>0.05)$. 
Table (3): Descriptive analysis and sex variation of analysis of facial heights in Class III group

\begin{tabular}{|c|c|c|c|c|c|c|c|}
\hline $\begin{array}{l}\text { Facial Height } \\
\text { Parameters }\end{array}$ & Sex & $\begin{array}{c}\text { Sample } \\
\text { No. }\end{array}$ & $\begin{array}{l}\text { Mean } \\
\text { Value }\end{array}$ & $\pm \mathrm{SD}$ & Significance & $\begin{array}{c}\text { Minimum } \\
\text { Value }\end{array}$ & $\begin{array}{c}\text { Maximum } \\
\text { Value }\end{array}$ \\
\hline \multirow{3}{*}{$\begin{array}{l}\text { Total Anterior } \\
\text { Facial Height }\end{array}$} & Male & 16 & 130.8 & 2.6 & A & 122.6 & 138.5 \\
\hline & Female & 16 & 129.6 & 2.4 & A & 122.0 & 136.0 \\
\hline & Total & 32 & 130.2 & 2.5 & $\mathrm{~A}$ & 122.0 & 138.5 \\
\hline \multirow{3}{*}{$\begin{array}{l}\text { Upper Anterior } \\
\text { Facial Height }\end{array}$} & Male & 16 & 56.4 & 2.2 & $\mathrm{~A}$ & 50.0 & 64.0 \\
\hline & Female & 16 & 54.8 & 2.6 & A & 47.5 & 61.5 \\
\hline & Total & 32 & 55.7 & 2.4 & A & 47.5 & 64.0 \\
\hline \multirow{3}{*}{$\begin{array}{l}\text { Lower Anterior } \\
\text { Facial Height }\end{array}$} & Male & 16 & 76.5 & 2.5 & A & 68.5 & 84.5 \\
\hline & Female & 16 & 74.7 & 1.8 & A & 66.5 & 81.5 \\
\hline & Total & 32 & 75.6 & 2.2 & $\mathrm{~A}$ & 66.5 & 84.5 \\
\hline \multirow{3}{*}{$\begin{array}{l}\text { Total Posterior } \\
\text { Facial Height }\end{array}$} & Male & 16 & 84.6 & 2.4 & A & 76.5 & 90.5 \\
\hline & Female & 16 & 80.8 & 2.2 & A & 75.5 & 91.0 \\
\hline & Total & 32 & 82.7 & 2.3 & $\mathrm{~A}$ & 75.5 & 91.0 \\
\hline \multirow{3}{*}{$\begin{array}{l}\text { Upper Posterior } \\
\text { Facial Height }\end{array}$} & Male & 16 & 46.2 & 1.9 & A & 34.5 & 49.5 \\
\hline & Female & 16 & 42.8 & 2.3 & A & 33.5 & 48.5 \\
\hline & Total & 32 & 44.5 & 2.1 & $\mathrm{~A}$ & 33.5 & 49.5 \\
\hline \multirow{3}{*}{$\begin{array}{c}\text { Lower Posterior } \\
\text { Facial Height }\end{array}$} & Male & 16 & 65.7 & 2.6 & $\mathrm{~A}$ & 52.0 & 73.5 \\
\hline & Female & 16 & 63.9 & 1.9 & A & 48.0 & 68.0 \\
\hline & Total & 32 & 64.8 & 2.3 & A & 48.0 & 73.5 \\
\hline
\end{tabular}

Analysis of variance of the facial height among the male, female and total sample was not significant $(p>0.05)$. Duncan's analysis of the facial height among the male, female and total sample was not significant $(p>0.05)$.

All measurements were in millimeters; SD: Standard deviation.

Different letters vertically mean significant difference $(p \leq 0.05)$.

Same letters vertically mean no significant difference $(p>0.05)$.

Table (4): Facial height variation analysis among the dentoskeletal groups

\begin{tabular}{|c|c|c|c|c|c|c|c|c|c|c|c|}
\hline \multirow{2}{*}{$\begin{array}{c}\text { Facial Height } \\
\text { Parameters }\end{array}$} & \multirow{2}{*}{ Sex } & \multirow{2}{*}{$\begin{array}{l}\text { Sample } \\
\text { No. }\end{array}$} & \multicolumn{3}{|c|}{ Class I } & \multicolumn{3}{|c|}{ Class II } & \multicolumn{3}{|c|}{ Class III } \\
\hline & & & Mean & \pm SD & Sig. & Mean & $\pm \mathrm{SD}$ & Sig. & Mean & $\pm \mathrm{SD}$ & Sig. \\
\hline \multirow{3}{*}{$\begin{array}{l}\text { Total Anterior } \\
\text { Facial Height }\end{array}$} & Male & 16 & 128.6 & 2.6 & $\mathrm{~A}$ & 136.4 & 1.6 & $\mathrm{~B}$ & 130.8 & 2.6 & A \\
\hline & Female & 16 & 126.2 & 2.1 & A & 134.2 & 1.4 & B & 129.6 & 2.4 & A \\
\hline & Total & 32 & 127.4 & 2.4 & A & 135.3 & 1.5 & B & 130.2 & 2.5 & A \\
\hline \multirow{3}{*}{$\begin{array}{l}\text { Upper Anterior } \\
\text { Facial Height }\end{array}$} & Male & 16 & 54.2 & 3.1 & A & 57.1 & 1.8 & A & 56.4 & 2.2 & $\mathrm{~A}$ \\
\hline & Female & 16 & 53.4 & 2.8 & A & 55.8 & 1.6 & A & 54.8 & 2.6 & A \\
\hline & Total & 32 & 53.8 & 2.9 & A & 56.5 & 1.7 & A & 55.7 & 2.4 & A \\
\hline \multirow{3}{*}{$\begin{array}{c}\text { Lower Anterior } \\
\text { Facial Height }\end{array}$} & Male & 16 & 71.2 & 3.2 & A & 78.3 & 2.2 & B & 76.5 & 2.5 & $\mathrm{~B}$ \\
\hline & Female & 16 & 69.3 & 3.1 & A & 76.9 & 2.4 & B & 74.7 & 1.8 & $\mathrm{~B}$ \\
\hline & Total & 32 & 70.3 & 3.1 & A & 77.6 & 2.3 & B & 75.6 & 2.2 & $\mathrm{~B}$ \\
\hline \multirow{3}{*}{$\begin{array}{l}\text { Total Posterior } \\
\text { Facial Height }\end{array}$} & Male & 16 & 90.3 & 2.8 & B & 96.6 & 1.8 & $\mathrm{C}$ & 84.6 & 2.4 & $\mathrm{~A}$ \\
\hline & Female & 16 & 87.5 & 1.9 & $\mathrm{~B}$ & 94.8 & 2.4 & $\mathrm{C}$ & 80.8 & 2.2 & A \\
\hline & Total & 32 & 88.9 & 2.3 & B & 95.7 & 2.1 & $\mathrm{C}$ & 82.7 & 2.3 & A \\
\hline \multirow{3}{*}{$\begin{array}{l}\text { Upper Posterior } \\
\text { Facial Height }\end{array}$} & Male & 16 & 48.4 & 3.4 & $\mathrm{~A}$ & 46.6 & 2.3 & $\mathrm{~A}$ & 46.2 & 1.9 & $\mathrm{~A}$ \\
\hline & Female & 16 & 44.8 & 2.9 & A & 42.9 & 1.9 & A & 42.8 & 2.3 & A \\
\hline & Total & 32 & 46.6 & 3.2 & A & 44.8 & 2.1 & A & 44.5 & 2.1 & $\mathrm{~A}$ \\
\hline \multirow{3}{*}{$\begin{array}{l}\text { Lower Posterior } \\
\text { Facial Height }\end{array}$} & Male & 16 & 58.3 & 2.4 & B & 51.2 & 1.9 & A & 65.7 & 2.6 & $\mathrm{C}$ \\
\hline & Female & 16 & 55.2 & 2.6 & B & 49.8 & 2.2 & A & 63.9 & 1.9 & $\mathrm{C}$ \\
\hline & Total & 32 & 56.8 & 2.5 & B & 50.5 & 2.1 & A & 64.8 & 2.3 & $\mathrm{C}$ \\
\hline
\end{tabular}

Analysis of variance of the facial height among the male, female and total sample was not significant $(p>0.05)$.

Duncan's analysis of the facial height among the male, female and total sample was not significant $(p>0.05)$.

All measurements were in millimeters; SD: Standard deviation; Sig.: Significance.

Different letters vertically mean significant difference $(p \leq 0.05)$.

Same letters vertically mean no significant difference $(p>0.05)$. 


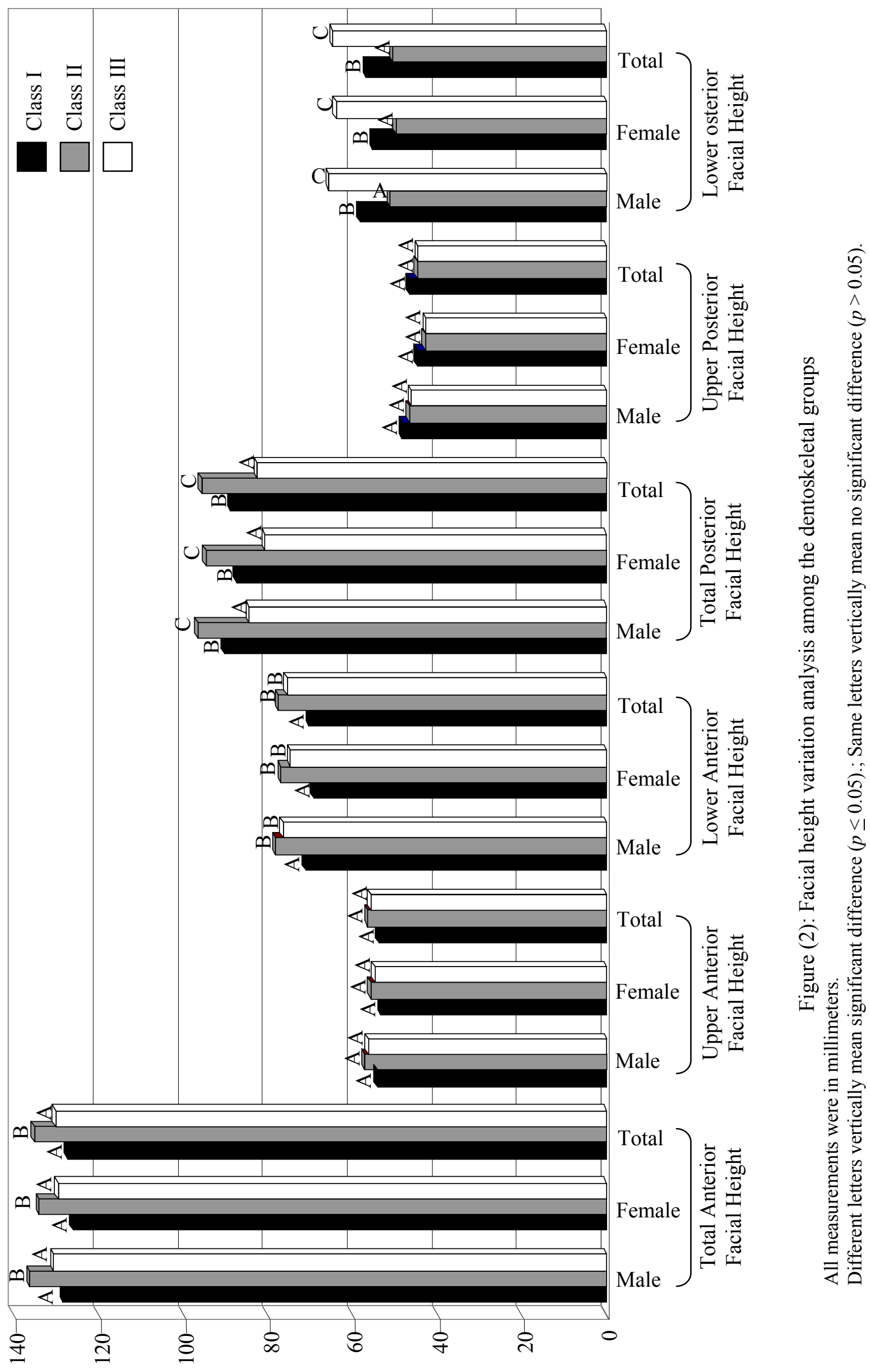


nificantly higher mean value $(p \leq 0.05)$ in the TPFH than in Class III group and significantly lower value $(p \leq 0.05)$ when compared with Class II group for both sexes and total sample. Meanwhile, Class I group was significantly greater mean value ( $p$ $\leq 0.05$ ) in LPFH when compared with Class II group for both sexes and total sample, whereas the LPFH in Class I group was significantly lower mean value than the Class III group for both sexes and total sample.

The comparison between Classes II and III groups appeared that the Class II group was significantly higher mean value $(p \leq 0.05)$ than Class III in the TAFH, TP$\mathrm{FH}$, meanwhile was insignificantly different $(p>0.05)$ mean value in UAFH, LAFH and UPFH, whereas was significantly smaller $(p \leq 0.05)$ mean value in LPFH for both sexes and total sample.

\section{DISCUSSION}

The increase mean values of the facial height parameters in male than female for the dentoskelatal groups could be due to that, generally, the vertical skeletal dimensions are relatively larger in males than females. This came in accordance with conclusions of other studies, ${ }^{(15,16)}$ which reported that the skeletal gender variation probably due to that male grow at faster rate and over long period of time than female.

The greater mean values that demonstrated in Class II group than Class I and III groups in all facial height parameters except the UPFH and LPFH for both sexes and total sample, and that increase mean values were appeared in Class III group than Class I group in all the facial height parameters except TPFH and UPFH for both sexes and total sample, indicating that the vertical growth patterns in the Class I, II and III groups generally are affected by the cranial base flexure and the position of the mandible. This was coordinated with that of Kasai et al., ${ }^{(17)}$ who reported that the variation in the anterior cranial base was associated with differences in the facial height. Hayashi ${ }^{(18)}$ stated that the morphology of the cranial base has an effect on the position of the mandible.

The insignificant differences $(p>$ $0.05)$ between sexes in all facial height pa- rameters for Class I, II and III groups could be explained by that growth pattern of facial heights are strongly associated with dentoskeletal subject regardless sex differences and the facial heights have relatively harmonious growth increment with both sexes, for each dentoskeletal groups. These coincided with that of Savoye et al., ${ }^{(19)}$ who concluded that the facial vertical proportions are high genetic determination. The results in Class I group were in contrast to the findings of the researchers ${ }^{(20,21)}$ for TAFH, TPFH and LPFH; and Al-Say$\mathrm{agh}^{(21)}$ for UAFH and LAFH. In Class II group the results were not matched with those of Al-Sammak ${ }^{(22)}$ regarding the TAFH, LAFH, TPFH and LPFH; and Al-Sul$\tan ^{(23)}$ concerning the UAFH and UPFH. In Class III group, the results were not coordinated with those of $\mathrm{Said}^{(24)}$ for UAFH, LAFH and TPFH.

The significantly high mean value ( $p$ $\leq 0.05)$ of TPFH in Class I group than Class III group and significantly decrease mean value $(p \leq 0.05)$ than Class II group for both sexes and total sample obviously due to mandibular rotation (anteriorly and upward in Class III group, and posteriorly and downward in Class II group) that could cause statistical variation in this facial parameter among the dentoskeletal groups. The TPFH difference between Class I and Class III coordinated the findings of Mouakeh, ${ }^{(25)}$ who reported that the Class III associated with significantly smaller vertical facial heights, whereas the results regarding Class I and Class II variation in TPFH were not coordinated the findings of Sayin and Turkkahraman ${ }^{(26)}$, who found that the TPFH significantly larger in Class I group than Class II group.

The significantly increase mean value of LPFH in Class I group than in Class II group, and the significantly decrease of LPFH in Class I group when compared with Class III group for both sexes and total sample were in agreement with that of Karlsen and Krogstad, ${ }^{(27)}$ who found short ramus length LPFH in Class II group; and Tom $^{(28)}$ was demonstrated significantly smaller LPFH in Class I group than Class III group.

The significantly greater mean value $(p \leq 0.05)$ of the TAFH, LAFH and TPFH in Class II group than Class III group for 
both sexes and total sample could be due to that cranial base bend and the forward rotation of the mandible in Class III group perform statistical decrease in these facial height. This came in accordance with conclusion of Mouakeh, ${ }^{(25)}$ who stated that the Class III group exhibited more acute (bend) cranial base angle NSBa. Klocke et $a l .{ }^{(29)}$ reported that the skeletal pattern of Class II group is characterized by increase TAFH. Kasai et al. ${ }^{(17)}$ found that the variation in anterior cranial base was associated with difference of the facial height.

The insignificant differences in the mean value of the UAFH and UPFH among the Class I, Class II group and Class III group for both sexes and total sample indicated that the growth increments change in the upper facial heights were not reach the statistical difference between these dentoskeletal groups.

\section{CONCLUSIONS}

The anterior and posterior facial heights had no significant sex variation and no significant difference among the dentoskeletal groups in the UAFH and UPFH. Class II group was significantly larger facial heights than Class I and Class III groups except UAFH, UPFH and LPFH and was significantly shorter than Class I and Class III groups in LPFH. Meanwhile, Class III group was significantly smaller facial height than Class I group in TPFH and was significantly larger in LAFH and LPFH.

\section{REFERENCES}

1. Canoon J. Craniofacial height and depth increment. Am J Orthod. 1970; 58: 202218.

2. Hellman M. The face in its developmental career. Dent Cosmos. 1935; 77: 685699. Cited by: Graber TM. Orthodontics; Principles and Practice. $3^{\text {rd }}$ ed. WB Saunders Co. Philadelphia. 1972; p: 15.

3. Weinman, JP, Sicher H. Bone and Bones. $1^{\text {st }}$ ed. CV Mosby Co. St Louis. 1955; p: 86 .

4. Enlow DH, Harris DB. A study of postnatal growth of the human mandible. Am J Orthod. 1964; 50: 25-50.

5. Woodside DG. Distance, velocity and relative growth rate standards for mandibular growth for Canadian males and fema- les age three to twenty years. American Board of Orthodontics Thesis, Toronto, Canada. 1969. Cited by: Graber TM. Orthodontics; Principles and Practice. $3^{\text {rd }}$ ed. WB Saunders Co. Philadelphia. 1972; p: 66.

6. Ibrahim Y, Aysequl I, Bulent B, Ismail C. Longitudinal posteroanterior changes in transverse and vertical structures between 10 and 14 years of age. Angle Orthod. 2004; 74: 624-629.

7. Steiner CC. Cephalometric for you and me. Am J Orthod. 1953; 39: 729-755.

8. Steiner CC. Use of cephalometry as an aid to planning and seen orthodontic treatment. Am J Orthod. 1960; 46: 721-743.

9. Wylie WL, Johnson EL. Rapid evaluation of facial dysplasia in vertical plane. Angle Orthod. 1952; 22: 162-182.

10. Biggerstaff RH, Allen RC, Tuncay OC, Berkowitz J. A vertical analysis of the human craniofacial complex. Am J Orthod. 1977; 72: 397-405.

11. Bjork A. The nature of facial prognathism and its relation to the natural occlusion of the teeth. Am J Orthod. 1951; 37: 106-124.

12. Rakosi T. An Atlas and Manual of Cephalometric Radiograph. $2^{\text {nd }}$ ed. Wolf Med Pub. 1982.

13. Fields HW, Proffit HW, Nixon WL, Phillio E, Stanek E. Facial pattern differences in long-faced children and adults. Am J Orthod. 1984; 85: 217-223.

14. Coben AM. The integration of facial skeletal variations: A serial cephalometric roentgengraphic analysis of craniofacial form and growth. Am J Orthod. 1955; 41: 407-434.

15. Bishara SE, Petrson LC, Bishara EC. Changes in facial dimension and relationships between the age of 5 and 25 years. Am J Orthod. 1984; 85: 238-252.

16. Marshall WA, Tanner JM. Variation in pattern of pubertal changes in girls. Archs Dis Child. 1969; 44: 291-303.

17. Kasai K, Moro T, Kanazawa E, Iwasawa T. Relationship between cranial base and maxillofacial morphology. Eur J Orthod. 1995; 17: 403-410.

18. Hayashi I. Morphological relationship between the cranial base and dentofacial complex obtained by reconstructive computer tomographic image. Eur J Orthod. 2003; 25: 385-391. 
19. Savoye I, Loose R, Carels C, Derom C, Vlietinck R. A genetic study of anteroposterior and vertical facial proportions using model-fitting. Angle Orthod. 1998; 68: 467-470.

20. Al-Hamadany AKh. Three-dimensional analysis of mandible in Class one normal occlusion of Iraqi adults in Mosul City (A cephalometric study). MSc thesis. College of Dentistry. University of Mosul. 2000.

21. Al-Sayagh NM. Dentoskeletal analysis and facial types of Iraqi adults in Mosul City with Class one normal occlusion (A lateral radiographic cephalometric study). MSc thesis. College of Dentistry. University of Mosul. 1999.

22. A1-Sammak SMA. Influence of craniofacial parameters on the mandible in Class II division 1 malocclusion (Three dimensional cephalometric study). MSc thesis. College of Dentistry. University of Mosul. 2005.

23. Al-Sultan MM. Cranial base parameters effect on the nasomaxillary complex in Class II division 1 malocclusion (Threedimensional cephalometric study). MSc thesis. College of Dentistry. University of Mosul. 2005.

24. Said RJ. The differential diagnosis of Class III malocclusion in adolescents of Mosul City (A radiographic cephalometric study). MSc thesis. College of Dentistry. University of Mosul. 2005.

25. Mouakeh M. Cephalometric evaluation of craniofacial pattern of Syrian children with Class III malocclusion. Am J Orthod Dentofac Orthop. 2001; 119: 640649.

26. Sayin MO, Turkkahraman H. Comparison of dental arch and alveolar width of patient with Class II division 1 malocclusion and subjects with Class I ideal occlusion. Angle Orthod. 2004; 74: 456-460.

27. Karlsen AT, Krogstad O. Morphological and growth in convex profile facial pattern: A longitudinal study. Angle Orthod. 1999; 69: 334-344.

28. Tom AP. Class III malocclusion: A cephalometric study of Saudi Arabians. Br J Orthod. 1989; 16: 201-206.

29. Klocke A, Nanda RM, Kahl-Nieke B. Role of cranial base flexure in the developing sagittal jaw discrepancies. Am J Orthod Dentofac Orthop. 2002; 122: 386-391. 